\title{
Impact of the Integrated Management Systems on the Achievement of Stable Quality and Safety of Biscuit Products
}

\author{
Marieta Stefanova, Denka Zlateva and Antoaneta Stoyanova \\ Department of Commodity Science, Faculty of Economics, Varna University of Economics, bul. Knyaz Boris I № 77, Varna BG-9002, \\ Bulgaria
}

\begin{abstract}
The implementation of Integrated Management System (IMS) of the quality management and safety is aiming to provide production of biscuit products corresponding to particular specification and client's requirements. This paper explores the possibilities of achieving stable sensory and microbiological parameters of the biscuits, through the implementation of IMS. An analysis was carried out of the factors affecting the achievement of stable quality. The achievement of the stability of the parameters of 150 different lots of biscuits has been measured before, during and after the implementation of IMS in the manufacturing company. The performed water activity analysis and sensory analysis confirmed that despite the dynamic changes in the internal and external environments as well as the significant changes in the requirements of the standards and the legislation, the implemented IMS has allowed the maintenance of the stable quality and safety of the biscuit products.
\end{abstract}

Key words: Food safety, quality management, sensory analysis, biscuit products, IMS.

\section{Introduction}

Biscuit products include a broad range of pasta prepared on the basis of flour, sugar and eggs [1]. The story of biscuits dates back to the time of Ancient Rome [2], and today the manufacturers of these products face the challenge to offer on the market a wide variety of biscuits with sustainable quality. The consumer preferences to these products are associated with their taste and high nutritional value determined by the content of sugar and fat [3].

The abundant opinions and approaches in the scientific literature regarding the control and management of technological processes allow us to say that the relationship between the quality management system and the sustainable quality of biscuits has not been fully explored [4-9].

The review of the literature has established that multiple factors influencing the increase of the quality

Corresponding author: Marieta Stefanova, Ph.D. student, research fields: food quality and safety management system. of biscuit products which have important theoretical and practical significance have been analyzed. The practical approaches for monitoring and controlling an Integrated Management System (IMS) are very diverse and vary from minimal to very strict controls applied in large industrial enterprises [10]. Usually such enterprises have laboratories performing multiple tests related to the safety, rather than the quality of the product.

The application of continuous monitoring or very frequent monitoring of the production processes has started in recent years and covers mainly the microbiological safety. The implementation of continuous monitoring of parameters associated with the sensory properties of the product has not found wide application. It was found that the control of the sensory properties of the product takes place only when the product is ready for shipment. In this final stage the only possible solution is to scrap the products that are below the manufacturing standard which leads to loss of significant resources. We 
believe that the introduction of an approach that ensures control and management at an early stage as well as the information provided in due time regarding any deviations from the indicators specified in the technical documentation would be an important precondition for achieving sustainable quality of finished products.

These and other aspects require introduction of control and management of the sustainable quality of biscuit products that would cover all production processes using an IMS. The scope of this systematic supervision should include measurement and control activities encompassing the processes from the supply of raw materials and their storage in controlled conditions to the shipment and sale of the finished product on the market.

The relation between quality and safety in food is intricate and although safety cannot [11] be viewed as a very independent aspect from quality. In fact, the reasoning behind separating food safety from quality was the need to place the concept of safety first above all the other quality aspects [12]. IMS is a term used in the present study and a management system, which combines a food safety management system and a quality management system.

The aim of this study is the implementation of a comprehensive new approach to the control and management of the technological processes by determining the level of impact of all steps in the production process using an IMS in order to ensure the achievement of sustainable quality of the finished product. The products covered by the IMS have very low moisture content and water activity, which guarantees their microbiological safety. For this reason, the confirmation of the adequacy of the applied control of IMS requires determination of the changes associated with the sensory properties and water activity (Aw).

\section{Materials and Methods}

This study was conducted in two Bulgarian factories producing exclusively biscuits. They supply the national and international markets, and currently the company employs over 870 employees working in production, administration and logistic areas. The factory has 11 production lines with a production capacity of approximately 185,000 boxes of biscuits per day.

The study covers one calendar year (from December 2015 to December 2016) and the researchers have visited the manufacturing sites repeatedly to get acquainted with the ongoing processes and to analyze the ways to achieve sustainable quality of biscuit products. The study data were collected during the monitoring of the various stages of the process, from receipt of raw materials to shipment of products. Additional information was obtained from accreditation laboratory analyses.

The test material used consisted of 150 different batches of biscuits produced before, during and after the implementation of the integrated system into the manufacturing site (1 month before, 1 month after, 2 months after, 3 months after, 9 months after the implementation of IMS). The test samples used to determine the sensory parameters are representative of the batch of the particular product. The samples were in the packaging intended for commercial distribution. Immediately before and during the test the samples were exposed to the typical conditions of storage and distribution (light, temperature and variations in relative humidity).

The main methods of analysis of the products used in the study are:

(1) Determination of Aw under ISO 21807 "Microbiology of food and animal feeding stuffs. Determination of water activity" [11].

(2) Sensory analysis was performed by the Descriptive Analysis [13].

(3) Examination by parameters: appearance, shape, surface, colour, texture, sectional surface, odour, taste and units/kg were carried out in accordance with standard manufacturer as follows:

- Shape. Diverse shapes, characteristic of each 
brand. The edges of the biscuits are either smooth or with curly patterns;

- Surface. Diverse surfaces, characteristic of each brand. The edges of the biscuits are either smooth or with curly patterns;

- Colour of the face side. Darker marks allowed on the protruding edges due to overbaking, but not burning. No deviations allowed;

- Colour of the underside. The overall hue of the colouring of biscuits in the same package must be uniform. The colour of the underside may be darker than that of the face side, but not from burning;

- Taste and odour. Pleasant, corresponding to the input ingredients, with no extraneous taste or odour. No deviation allowed;

- Surface upon breakage. Pronounced porous structure. No deviation allowed. In sandwiched biscuits the filling should not protrude out of the biscuits.

The used indication of coherence of the sensory evaluations is the coefficient of variation ( $\mathrm{V}, \%)$, which gives information about the variation of the sensory assessments of the parameters in percentage. It is considered that the variation is low (the assessments are homogeneous), when its value is below $15 \%$. When it is between $15 \%$ and $30 \%$ it is considered that the assessments are almost homogenous. When it is over $30 \%$, the variation is high (the assessments are highly heterogeneous).

The study was based on the qualitative approach and constituted a thorough analysis of the situation and the state of quality management under real conditions. After carrying out observation of the interaction between the processes and the necessary control, an analysis was performed that cannot be interpreted by quantitative methods. A qualitative study was performed based on the methodology developed by Patton [14].

\section{Results and Analysis}

\subsection{Characterization of the Study}

It is well known that the production process in the confectionary industry has been significantly automated in recent decades and many enterprises have introduced continuous monitoring of the parameters that are critical to product safety. This trend, however, does not lead to an increase in the number of persons involved in control. In many cases, technological control is carried out by one or more persons who rather register deviations and may not take decisions to dispose with a product when it does not comply with the critical quality parameters.

In most cases, batches are scrapped and destroyed when the controller finds that the values of the reported parameters have deviated from the critical limits related to product safety. The research literature abounds in mathematical formulas and methods for statistical quality control. In practice, no statistically significant analyses of a large number of batches or of representative samples of the products are made in the process of technological control which in turn leads to substantial deviations in the sensory properties of a product.

Usually, when new technologies and automated equipment are introduced there is no research about how this change will affect the quality of products. Examples can be given about how the introduction of automated processes has cut down the time for baking or cooling biscuits, which does not allow the formation of the necessary and expected sensory properties of the product.

These preconditions require the introduction of a new model for control and management of the technological processes focusing on the critical parameters that may affect unfavorably the sensory analysis and increase the value of the measured water activity. The control and management of the technological processes using an IMS proposed by us covers all steps in the production of biscuits with a new model for its development and continuous improvement.

\subsection{Control Model}

The main purpose of introducing IMS is to achieve, 
on the one hand, conformity of the product with the established regulatory and industry standards, and customer satisfaction, on the other hand. Consumer expectations are associated with the implementation of the regulatory requirements and the sustainable quality of the products that are commercially available. Consumers would not be satisfied if the sensory properties of a product offered in the same package differed even if the properties have been improved.

Control and management of the technological processes using an IMS was introduced after comprehensive research and covers six stages as presented in Fig. 1. The goals of control are achieved after defining and planning in advance the object that will be measured, where and when it will be measured and what methods will be used. The achievement of the goals is measured using the processes of validation and verification of the food safety management system and ensuring that the developed system has reached the expected level of control. The measurements take place under controlled conditions and using appropriate calibrated or verified means of control and measurement. The planned control actions are carried by monitoring every step of the technological process on the basis of the performed hazard analysis. The monitoring activities include planned real-time observations or measurements.

The information from the monitoring allows for assessment of whether the introduced control measures function as designed at stage one so as to prevent deviation from the critical limits. The monitoring activities in the organization consist in: measurements and observations providing results within a given timeframe; processing of the information to determine

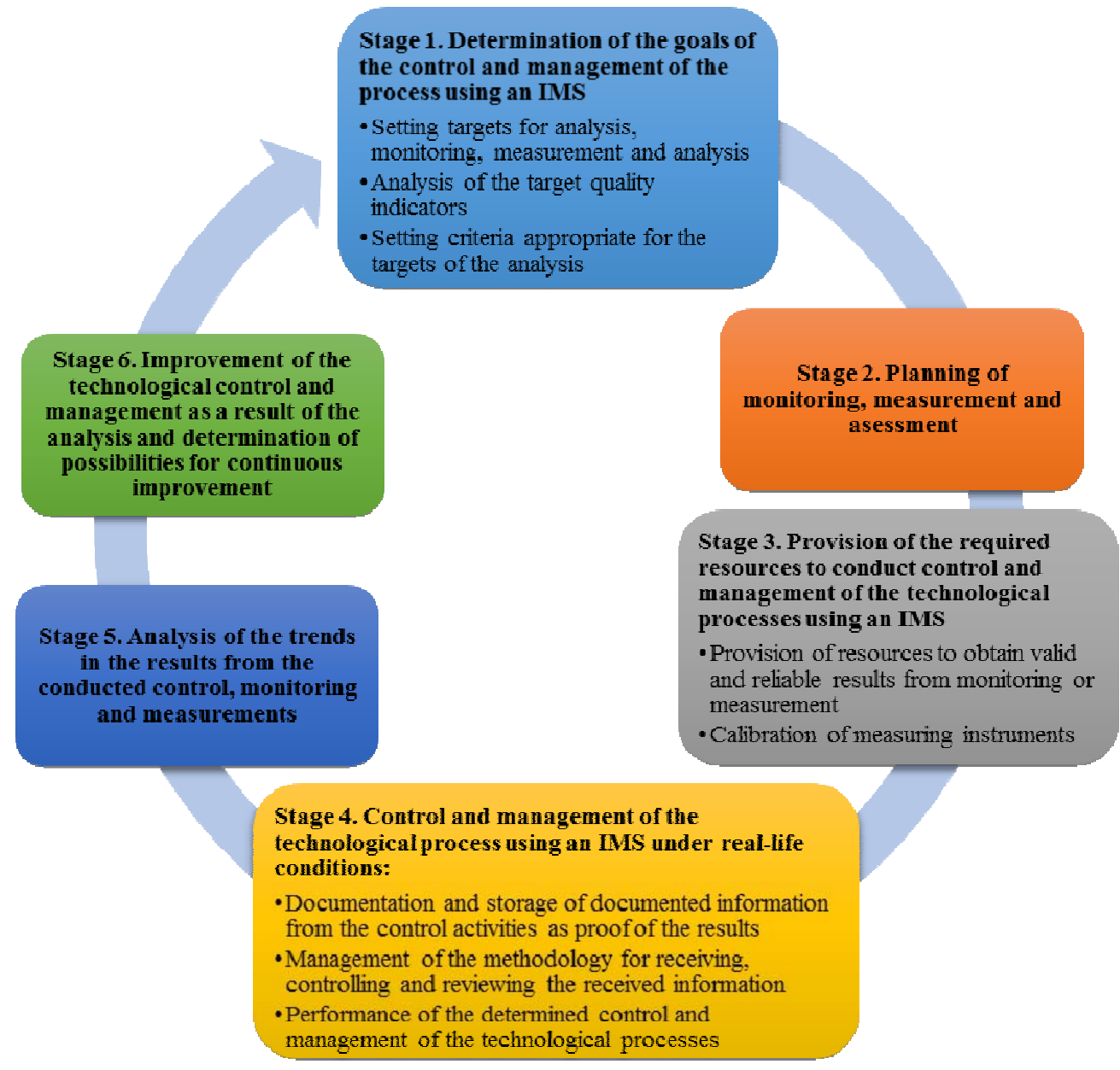

Fig. 1 Model of control and management of the technological processes. 
the corrective actions and to provide data for assessing the effectiveness of the system for management of the quality and safety of the food products.

As the figure shows, the control and management of the technological processes can be decomposed as follows:

Stage 1. Determination of the goals of the control and management of the technological process an IMS.

Setting goals. The purpose of the introduced process control is to maintain sustainable production in stable conditions while minimizing impacts or increasing the influence of the process in the different technological steps.

Analysis of the target quality indicators. The main goal of introducing a management system is to achieve customer satisfaction, which defines the set of selected indicators within the scope of the monitoring. The planned monitoring is based on the impact of each step in the manufacturing process on the ensuring of sustainable quality indicators in terms of sensory analysis and safety of the finished products.

Determination of criteria suitable for the purposes of the analysis. A necessary condition to implement control is to identify the internal and external boundaries of the target value formed as a result of the impact of the processes. This is achieved by making a series of continuous measurements of biscuits and determining their specification. The most important measurements in the whole production process in terms of product safety are performed on freshly baked products at the exit of the belt furnace. The steps in the technological process using an IMS of biscuits production are presented in stage 4 as well as the measurements of different parameters.

Stage 2. Planning of monitoring, measurement and assessment.

The monitoring can be continuous or at regular intervals and the method of monitoring must deliver fast and accurate results on whether the process is under control. The food safety system contains specific corrective actions when the monitoring shows that it is possible for the process or step to deviate from the critical limits or if there is no compliance with the preconditions. The control of the technological process in the studied sites consists of measurements and monitoring providing results within a specific time frame. The control activities allow for monitoring of the progress in the implementation of the specifications set out in the technological documentation.

Stage 3. Provision of the required resources to conduct control and management of the technological processes using an IMS.

Provision of resources for valid and reliable results from monitoring or measurement. The control of the technological processes management in most biscuits factories is entrusted to the technological department. The setting up of such units should be seen as a very good investment, a source for generation of innovative products, a source of ideas for reducing costs and achieving sustainable quality of already manufactured products. The high qualification of the staff in the technological department is a prerequisite for the successful management of the production processes with minimization of the costs resulting from scrapped and inedible food products.

To achieve the goals of quality control it is necessary to create also a laboratory. The size and scope of this laboratory depend on the breadth and depth of the product assortment. If the laboratory should make also tests of incoming raw materials, then the scope becomes significantly larger. A necessary condition to achieve the planned goals of control is to conduct taste tests in the laboratories. Setting up a laboratory for sensory analysis should be tied not only to the provision of material and technical basis for such tests, but also to the provision of methodologies. Increasing the qualification of the experts who conduct sensory tests would increase the reproducibility of the results of the analyses made.

Calibration of the resources for monitoring and measuring. Measurements are conducted under 
controlled conditions and using appropriate calibrated or verified tools for monitoring and measurement. An important difference between the ISO editions on quality management systems ISO 9001:2008 and ISO 9001:2015 is the replacement of the term "measuring equipment" with "resources for monitoring and measuring”. The main reason for this change is that organizations that implement quality management systems often have sensory tests carried out by experts that cannot be treated as measuring equipment. The change requires creation of the necessary conditions for improving the qualification of the experts involved in sensory evaluations. This makes the implementation of the latest version of the standard difficult because, on the one hand, the employment of such specialists with proven sensory sensitivity is a very large investment and often there are no such specialists on the market, and on the other, there are no licensed courses where companies can send their available staff for training. The solution to this problem can be sought in the use of accredited laboratories for sensory assessment. Sending the products to an accredited laboratory, the performance of the test and the obtaining of the result take at least one or two days. Therefore, the use of such laboratories is not very appropriate. The control of the technological processes, including the sensory assessments, needs to be conducted in due course. They become meaningless if the results are available when production has been fully packed and ready for shipment. Therefore, at this stage, biscuits manufacturers need to create their own sensory laboratories and to seek ways to qualify the staff employed in them.

Stage 4. Control and management of the technological process under real-life conditions.

Documentation and storage of the documented information on the control measures as proof of the results. One advantage of the rapid development of modern technologies is the decreasing cost of personal computers and mobile applications that currently are not a luxury and can be provided in technological laboratories. The electronic control system allows for quick sorting and generation of information and instant access to legislative requirements, information on counterfeit or forged raw materials, analysis certificates, accreditations and information about particular specifications and formulations. Ensuring that the laboratory for technological control and quality management is subscribed to scientific and applied databases is a prerequisite for obtaining quick and adequate information on the control to be conducted.

Management of the methodology for receiving, monitoring and reviewing the received information. The performance of analyses requires methodological guidelines for the conduct of control and management of the technological processes established on the basis of the generated databases.

Performance of the prescribed control and management of technological processes using an IMS. The purpose of conducting control is to ensure that products are manufactured according to the specifications, in compliance with the legal requirements and good manufacturing practices for quality and safety. In this connection other indicators can also be tested that have not been subject of the HACCP study, such as appearance of the products, taste, texture, package integrity, etc. The frequency and type of product tests are a prerogative of every manufacturer and are determined by the degree of the risk associated with product safety including by the specific requirements of customers and consumers. The control and management steps that are introduced with the IMS at every state of the technological process are listed in Table 1.

Stage 5. Analysis of the trends in the results from the conducted control, monitoring and measurements

The food safety team monitors every step of the technological process on the basis of the planned actions for control and the developed methodology manuals. The monitoring activities include planned 
Table 1 Impact of manufacturing processes using an IMS on the sustainable quality of biscuits.

\begin{tabular}{|c|c|}
\hline Stages of production & Applied control and settings of the equipment in the integrated system \\
\hline $\begin{array}{l}\text { Acceptance of raw } \\
\text { materials for contact } \\
\text { with foods }\end{array}$ & $\begin{array}{l}\text { physicochemical analysis or existent certificate of analysis from the manufacturer; } \\
\text { microbiological analysis and water activity; } \\
\text { presence of accompanying documents; } \\
\text { markings for shelf life and minimum durability on the package; } \\
\text { presence of physical contaminants; } \\
\text { presence of the wetted packaging; } \\
\text { sensory properties: smell and taste typical of the raw material; } \\
\text { measurement of water activity and moisture before authorizing the storage of the raw material in the } \\
\text { warehouses of the company. }\end{array}$ \\
\hline $\begin{array}{l}\text { Storage of raw } \\
\text { materials }\end{array}$ & $\begin{array}{l}\text { relative humidity in the storage room up to } 75 \% \text {; } \\
\text { temperature in the storage room up to } 26^{\circ} \mathrm{C} \text {; } \\
\text { temperature in refrigeration chambers-from } 0{ }^{\circ} \mathrm{C} \text { to } 4{ }^{\circ} \mathrm{C} \text {; } \\
\text { indicator for remaining shelf life; } \\
\text { separate storage of spices and nuts to prevent cross-contamination. }\end{array}$ \\
\hline \begin{tabular}{|l|} 
Transportation to \\
processing sites
\end{tabular} & $\begin{array}{l}\text { integrity of transport packaging; } \\
\text { contamination during transport (physical, chemical and biological). }\end{array}$ \\
\hline $\begin{array}{l}\text { Dosing of raw } \\
\text { materials }\end{array}$ & $\begin{array}{l}\text { compliance with production recipe for each product; } \\
\text { monitoring of drinking water; } \\
\text { inspection of the hygiene of the personnel and of the technological equipment; } \\
\text { check if the filter of the flour silo is clean before each delivery; } \\
\text { execution of the sequence of raw materials input as per recipe. }\end{array}$ \\
\hline $\begin{array}{l}\text { Whipping and/or } \\
\text { kneading }\end{array}$ & $\begin{array}{l}\text { visual inspection to determine the homogenization of the raw materials; } \\
\text { duration of the process in the range of } 15-20 \text { minutes depending on the quantity of the dough (acc. } \\
\text { production recipe); } \\
\text { correct dosage of raw materials and flour acc. production recipe: automatically (from the silo) or manually; } \\
\text { visual inspection of the homogeneity; } \\
\text { check the dough with metal detector for presence of physical metal contaminants. }\end{array}$ \\
\hline Molding & $\begin{array}{l}\text { the speed of the molding machine belt; } \\
\text { the position of the knife relative to the shaft (for adjusting the weights); } \\
\text { the frequency of cutting done by the knife of the automatic squirt gun; } \\
\text { tightening of the shaft to the molding belt; } \\
\text { visual inspection of the appearance (integrity); } \\
\text { weight determined for each product (A sample of } 10 \text { biscuits is taken for each bowl of mixed dough); } \\
\text { visual inspection of the homogeneity of the dough. }\end{array}$ \\
\hline Glazing & $\begin{array}{l}\text { rotation speed of the shafts of the glazing device; } \\
\text { distance between the shafts of the glazing device; } \\
\text { visual inspection of the appearance; } \\
\text { thickness of the glaze layer. }\end{array}$ \\
\hline $\begin{array}{l}\text { Sprinkling after } \\
\text { molding }\end{array}$ & $\begin{array}{l}\text { rotation speed of the sprinkling shaft; } \\
\text { speed of the conveyor belts. } \\
\text { visual inspection of the appearance; } \\
\text { thickness and uniformity of the sprinkles. }\end{array}$ \\
\hline $\begin{array}{l}\text { Baking in conveyor } \\
\text { belt/rotary furnaces }\end{array}$ & $\begin{array}{l}\text { temperature in the conveyor belt or rotary furnace; } \\
\text { speed of the wire mesh conveyor belt; } \\
\text { degree of opening of the vent openings; } \\
\text { temperature of the product at the exit of the belt furnace from } 80{ }^{\circ} \mathrm{C} \text { to } 130{ }^{\circ} \mathrm{C} \text {; } \\
\text { duration of baking from } 5 \text { to } 20 \text { minutes; } \\
\text { visual inspection of the baked product; } \\
\text { colour of the product after baking, including the colour of the upper and lower surface; } \\
\text { shape and taste of the baked product. }\end{array}$ \\
\hline Cooling after baking & $\begin{array}{l}\text { adjusting the degree of opening of the air suction; } \\
\text { speed of the conveyor belts; } \\
\text { cooling time according to the product type; } \\
\text { temperature of cooled product; } \\
\text { appearance, colour, shape and taste of the finished product. }\end{array}$ \\
\hline
\end{tabular}



Stable Quality and Safety of Biscuit Products

(Table 1 continued)

\begin{tabular}{|c|c|}
\hline Stages of production & Applied control and settings of the equipment in the integrated system \\
\hline Cream laying & $\begin{array}{l}\text { speed of the conveyor belts; } \\
\text { speed of the "wet” wire mesh conveyor belt—-to reach the specified weight; } \\
\text { weight per unit of product (measured before and after laying cream); } \\
\text { visual inspection—-shape and thickness of the cream layer. }\end{array}$ \\
\hline $\begin{array}{l}\text { Sprinkling after laying } \\
\text { the cream }\end{array}$ & $\begin{array}{l}\text { regulating the rotation speed of the sprinkling shaft; } \\
\text { weight per unit of product (measured before and after sprinkling); } \\
\text { visual control of the thickness and uniformity of the sprinkles layer. }\end{array}$ \\
\hline $\begin{array}{l}\text { Cooling after laying } \\
\text { the cream }\end{array}$ & $\begin{array}{l}\text { temperature of the cooling tunnel; } \\
\text { speed of conveyor belts; } \\
\text { temperature of the cooled product. }\end{array}$ \\
\hline Coating & $\begin{array}{l}\text { speed of conveyor belts; } \\
\text { speed of the "wet" wire mesh conveyor belt—-to reach the specified weight; } \\
\text { blowing rate and height of the fan of the coating module; } \\
\text { visual inspection of the adhesion; } \\
\text { shape and colour of the coated product; } \\
\text { temperature of the glaze- }-40^{\circ} \mathrm{C} \text { to } 50^{\circ} \mathrm{C} / \text { thermometer on the machine, thermostat. }\end{array}$ \\
\hline $\begin{array}{l}\text { Cooling of the end } \\
\text { product }\end{array}$ & $\begin{array}{l}\text { speed of conveyor belts; } \\
\text { temperature of the cooled coated product, which should be in the range }+6^{\circ} \mathrm{C} \text { to }+22{ }^{\circ} \mathrm{C} \text {; cooling time in a } \\
\text { cooling tunnel from } 5 \text { to } 20 \text { minutes; temperature of the cooled non-coated product, which should be in the } \\
\text { range of }+10^{\circ} \mathrm{C} \text { to }+40^{\circ} \mathrm{C} \text {; } \\
\text { cooling time from } 10 \text { to } 40 \text { minutes; } \\
\text { weight of the product after coating and cooling. }\end{array}$ \\
\hline $\begin{array}{l}\text { Arrangement and } \\
\text { weight control }\end{array}$ & $\begin{array}{l}\text { visual check for presence of condensation; } \\
\text { sensory evaluation of the shape of the biscuit; } \\
\text { evaluation of the integrity of the pad; } \\
\text { contamination of packaging materials; } \\
\text { evaluation of the conformity between the type of product and type of packaging; } \\
\text { conformity of the weight of the pre-packaged net quantity measured by calibrated electronic scales. }\end{array}$ \\
\hline $\begin{array}{l}\text { Check the end product } \\
\text { with metal detector of }\end{array}$ & $\begin{array}{l}\text { conducting tests using benchmarks to check the performance of the detector; } \\
\text { the introduction of metal detectors able to detect metal particles with sizes larger than } 7 \mathrm{~mm} \text { is good } \\
\text { manufacturing practice in the industry and is part of the quality and product safety control. }\end{array}$ \\
\hline Packaging & $\begin{array}{l}\text { speed of packaging; } \\
\text { temperature of the cutting blades according to the thickness of the foil; } \\
\text { length of the package according to the product type; } \\
\text { controlling the packaging operation; } \\
\text { conformity of the packages with the specification of the finished product; } \\
\text { accuracy of the labeling of the product; } \\
\text { integrity of the packaging; } \\
\text { proper labeling and marking; } \\
\text { correct indication of batch number and date of minimum durability. }\end{array}$ \\
\hline $\begin{array}{l}\text { Final inspection of the } \\
\text { finished product }\end{array}$ & $\begin{array}{l}\text { sensory control with frequency three times in eight hours; } \\
\text { internal physicochemical control three times in eight hours; } \\
\text { determining the moisture content; } \\
\text { determining the water activity; } \\
\text { proof of conformity with the specification. Products that cannot be identified as conforming will not be } \\
\text { accepted for final inspection: they need to be subjected to repeated control until their compliance with the } \\
\text { requirements set out in the technological documentation is confirmed, or are scrapped; } \\
\text { validation of the shelf life of the product. }\end{array}$ \\
\hline Storage & $\begin{array}{l}\text { integrity of the package; } \\
\text { proper arrangement of the finished products on pallets; } \\
\text { monitoring the remaining shelf life and durability; } \\
\text { temperature of the storage room up to } 26^{\circ} \mathrm{C} \text { and relative humidity of the air in the storage room up to } 75 \% \text {. }\end{array}$ \\
\hline Shipping & $\begin{array}{l}\text { integrity of the packaging; } \\
\text { proper arrangement of the finished products on pallets in the transport vehicle; } \\
\text { hygiene control of the vehicle. }\end{array}$ \\
\hline Transportation & $\begin{array}{l}\text { integrity of the package and pallet; } \\
\text { proper arrangement of the pallets; } \\
\text { cleanliness of the transport vehicles. }\end{array}$ \\
\hline
\end{tabular}


real-time observations or measurements. The monitoring information makes it possible to assess whether the control measures put into place operate as designed (in the plan according to HACCP on Critical Control Points-CCP and the Prerequisite Operational Programmes-POP) so as to prevent deviation from the critical limits.

The company analyzes and evaluates the relevant data and information resulting from the monitoring and measurement to assess the conformity of products and services, the level of customer satisfaction, the quality of work and the efficiency of the quality management system.

After the control the information is processed to determine any corrective action. The undertaken control measures allow the provision of data to assess the efficiency of the quality management system and the food safety. The trends in the results from the exercised control are analyzed in the management review on a yearly basis.

Stage 6. Improvement of the technological control and management as a result of the analysis and determination of possibilities for continuous improvement

As already explained, the main purpose of the control and management of processes is to prevent the marketing of products that do not meet the specification on the market. The product specifications are updated depending on the requirements of the consumers and are regularly reviewed as required by the company policy for continuous improvement.

The conducting of laboratory tests confirming all specifications of the product is very difficult, very expensive and requires at best a few days. When the products are in small batches (from 3,000 to 4,000 pieces) conducting all analyses would exceed many times the profit from the sale of the product, moreover, too many products would be needed to conduct the analyses.

These reasons require that any change in the product specification should be based on new methods or modifications or improvement of existing ones in order to ensure that the purposes of control will be achieved. The control and management of the production process using an IMS must monitor the critical parameters that can affect the product specifications.

The requirements for continuous sustainable quality and safety of biscuit products are achieved through compliance with the activities regulated in each step of the production process using an IMS. The frequency and scope of the control are determined depending on the influence of a particular technological stage on the quality of the finished products. The forms of control in every step of the production process are the basis for developing the management rules laid down in the IMS. The maintenance and continuous improvement of the IMS by controlling the steps of the manufacturing process is a necessary and sufficient condition for achieving sustainable results in the control of the sensory and microbiological parameters of the products.

A main requirement to all controlled processes using an IMS is the need to make regular assessments for compliance with the output level. An important part of the specification of biscuit products is printed as information on the product package. Usually the manufacturers of these products print a large number of packages in order to make economies of scale. This allows the control and monitoring of the product to be constantly improved in terms of accuracy and precision.

The process of validation (confirmation) creates certainty that the combination of control measures laid down in the production process using an IMS of biscuits allows reaching the expected results. Before implementation of the control measures presented in Table 1 it should be confirmed that: the selected control measures are able to achieve the expected control on the envisaged risks; the control measures are efficient and can create conditions for sustainable quality of the production. 
The upward deviation from the values of the indicator Aw (above 0.61) can compromise the safety the product due to the vital activity of microorganisms which have a lower threshold of the indicator Aw below which they cannot develop (Aw must be < 0.61 ). The deviations in the sensory characteristics of the finished products would lead to non-conformities in terms of the product specifications and the level of satisfaction of the customers' requirements and expectations, which in turn would destabilize the market positions and would worsen the financial indicators of the producer.

The analyses performed in an accredited laboratory confirm that the biscuit products have no increase in the values of the indicator Aw. Higher values of water activity are observed in the products Zeffo-Milk coating; Jam-Bi Strawberry; Yana with Marmalade; Medenki; Zeffo with Coconut, Happy Choice berries, for which there are measured values between 0.466 and 0.608 . All measured values of the indicator Aw of the studied 150 products are below 0.61. This guarantees that their safety has been confirmed.

The verification of the adequacy of the control proved that the system operates as designed according to the performed tests. The verification (check) is defined as the application of methods, procedures, tests and assessments in addition to the monitoring of the processes in order to determine whether a control measure is functioning as intended.

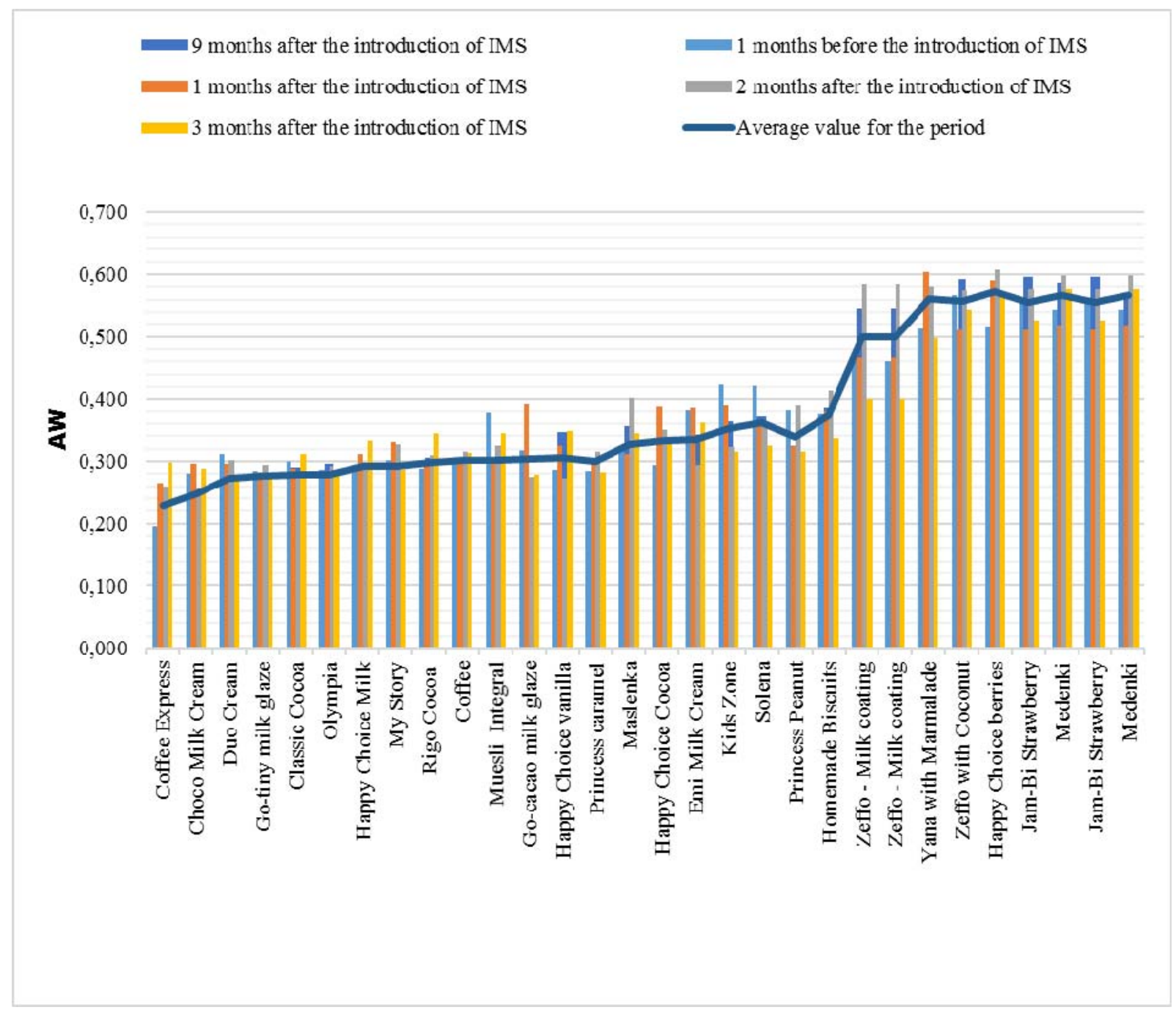

Fig. 2 Results from the Aw analysis performed on biscuits. 
The analyses made at an accredited laboratory confirm that the biscuits produced during different periods of time have a permanent and unchanging quality after the introduction of the control system as part of the IMS.

The results of the sensory analysis of biscuit products in accreditation laboratory analyses:

Deviations from the specified parameters were registered in 3 of the 150 different products examined:

- One of the ten biscuits was structurally damaged.

- One of the ten biscuits in the package had small minor damage to the upper surface;

- One of the ten biscuits sticks in the package was broken and crushed.

The performed sensory analyses of 150 different batches of biscuits confirm that, with small deviations before the introduction of the IMS, the products have stable sensory properties.

Results of the profile analysis on various indicators are formed in a closed procedure.
As it can be seen from the results presented in Figs. 3-5, sensory analysis conducted before, during and after the implementation of IMS prove, that there are no significant changes in the sensory quality of biscuits. The average estimates of the experts fluctuate in the range of 4.40 to 5.00 . These results confirm that despite the numerous negative factors affecting the internal and external environments and risks to the safety and quality, biscuits are with relatively stable sensory indicators.

Following the calculations made, it was found that the values of $\mathrm{V}(\%)$ are $6.45 \%$ and $11.73 \%$, which gives us a reason to believe that the variation is really low. The control exercised as part of the quality and product safety management system through an integrated approach could not only protect the interests of consumers by ensuring the quality of the product but could also develop a comprehensive quality management system of the organization's activities.

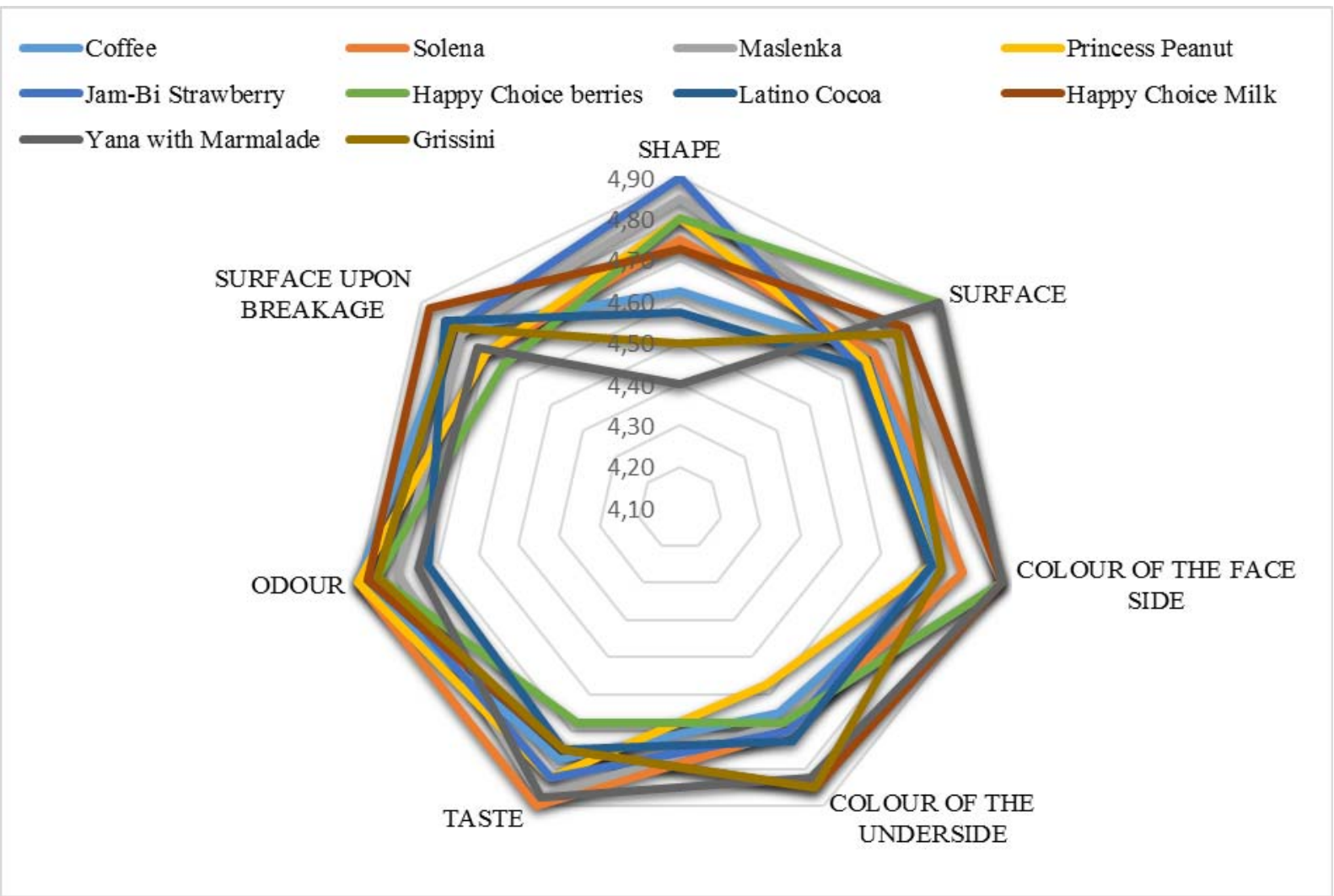

Fig. 3 Results from the sensory analysis performed on biscuits No. 1 to No. 10. 

Stable Quality and Safety of Biscuit Products

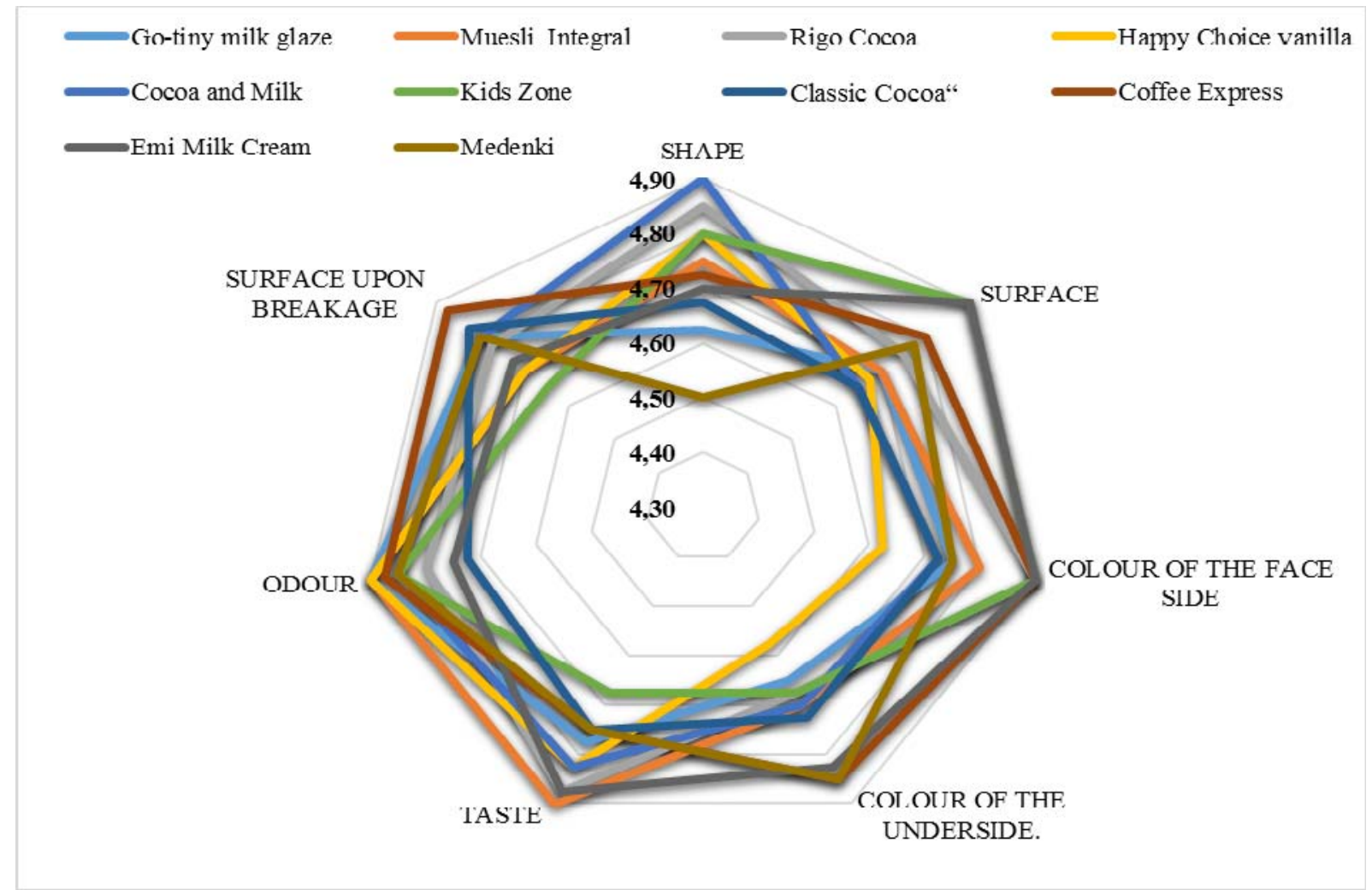

Fig. 4 Results from the sensory analysis performed on biscuits No. 11 to No. 20.

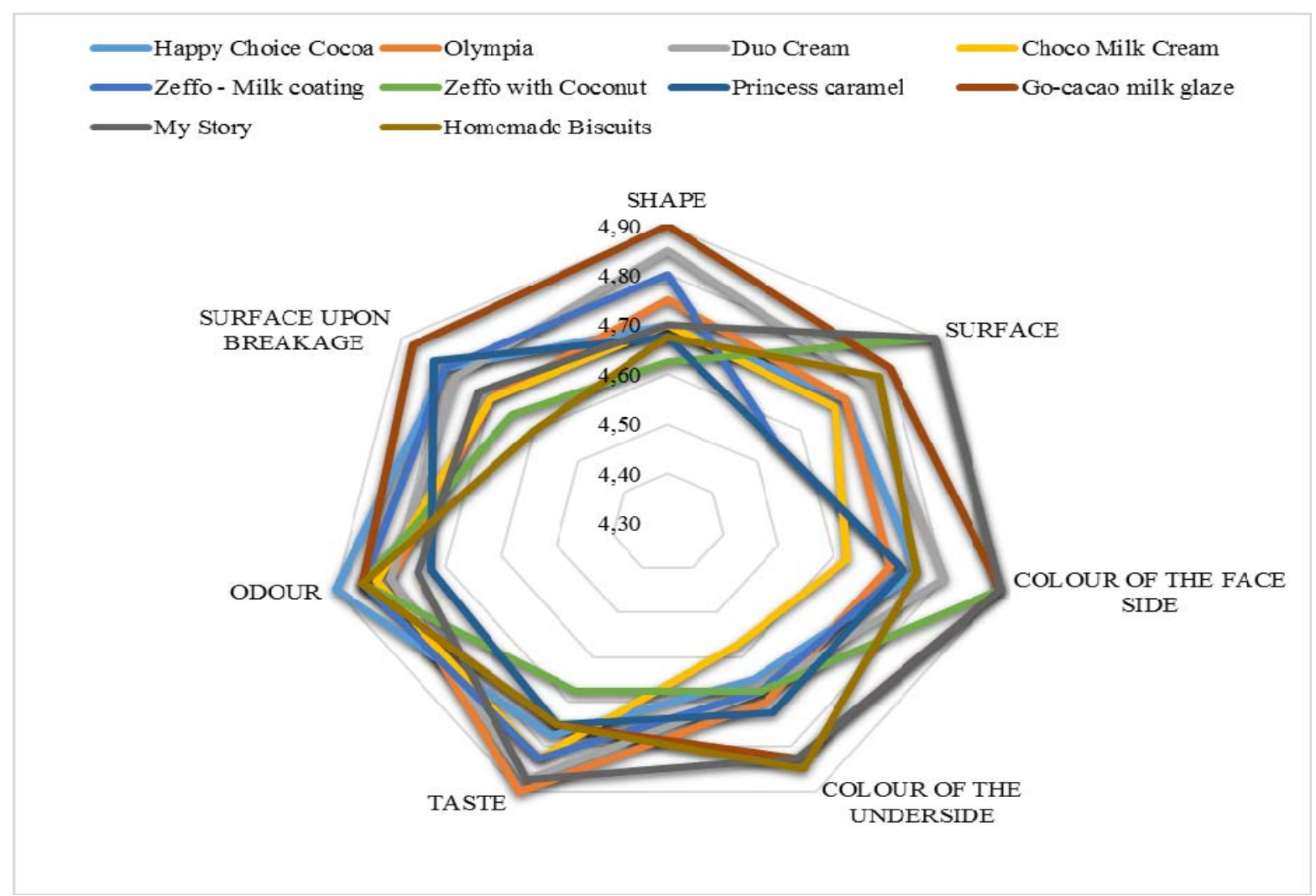

Fig. 5 Results from the sensory analysis performed on biscuits No. 21 to No. 30. 


\section{Conclusions}

The implementation of the quality management system can create the necessary and sufficient conditions to meet the compliance requirements. The exercise of adequate control as part of the overall IMS is an important condition to ensure minimizing the risk of having end products which do not comply with the regulatory requirements and the specifications. Sustainability of sensory parameters was registered in 150 different batches of biscuits produced before, during and after the introduction of the integrated system within the manufacturing facility. The Aw and sensory analyses performed confirmed that despite the numerous risks in the production of biscuits able to affect the quality of finished products and the sustainability of parameters, the implemented IMS allows maintaining sustainable quality of the biscuit products.

\section{Acknowledgements}

We would like to express our gratitude to ZIV Ltd., Bulgaria for giving us the opportunity to use for the study products produced in their factories during the period before, during and after the implementation of IMS.

\section{References}

[1] Manley, D. 2011. Manley's Technology of Biscuits, Crackers and Cookies. 4th ed. Oxford: Elsevier.

[2] Pyler, E., Gorton, A., Roda, A., and Teresa, M. 2008. Baking Science \& Technology/Baking Science and Technology. 4th ed. Kansas City: Sosland Pub.

[3] Tarancón, P., Fiszman, S., Salvador, A., and Tárrega, A. 2013. "Formulating Biscuits with Healthier Fats.
Consumer Profiling of Textural and Flavour Sensations during Consumption.” Food Research International 53 (1): $134-40$.

[4] Talbot, G. 2009. Science and Technology of Enrobed and Filled Chocolate, Confectionery and Bakery Products. Oxford: Elsevier.

[5] Allais, L., Perrot, N., Curt, C., and Trystram, G. 2007. "Modelling the Operator Know-How to Control Sensory Quality in Traditional Processes." Journal of Food Engineering 83 (2): 156-66.

[6] Ahmad, S., Saiyad, S., Morgan, M., and Okos, M. 2001. "Effects of Microwave on the Drying, Checking and Mechanical Strength of Baked Biscuits.” Journal of Food Engineering 50 (2): 63-75.

[7] Siddiqui, A., and Nasreen, L. 2014. "Effects of the Baking Temperature and Time on the Quality of Biscuits.” Journal of State University of Bangladesh 5 (1): 1-12.

[8] Manley, D. 1998. Biscuit, Cookie, and Cracker Manufacturing, Manual 1: Ingredients. Vol. 1. London: Woodhead Publishing.

[9] Manohar, S., and Haridas, R. 1997. "Effect of Mixing Period and Additives on the Rheological Characteristics of Dough and Quality of Biscuits.” Journal of Cereal Science 25 (2): 197-206

[10] Van der Spiegel, M., Ziggers, G. W., and Luning, P. A. 2005. "Evaluation of Performance Measurement Instruments on Their Use for Food Quality Systems.” Critical Reviews in Food Scince and Nutrition 44 (7): 501-12.

[11] ISO, ISO 21807, 2004. Microbiology of Food and Animal Feeding Stuffs-Determination of Water Activity. 1st ed. Geneva: International Organization for Standardization.

[12] Rotaru, G., Borda, D., and Stanciu, S. 2005. "Food Quality and Safety Management Systems: A Brief Analysis of the Individual and Integrated Approaches.” Scientifical Researches: Agroalimentary Processes and Technologies 11 (1): 229-36.

[13] Poste, L. M., Mackie, D. A., Butler, G., and Larmond, E. 1991. Laboratory Methods for Sensory Analysis of Food. Ottawa: Canada Communication Group.

[14] Patton, M. 1987. How to Use Qualitative Methods in Evaluation. 4th ed. Thousand, California: Sage. 